\title{
A New Filtering Method and a Novel Converter Transformer for HVDC System.
}

\author{
Mr.A.Hema Sekhar,M.Tech.,(Ph.D), Dr.A.Lakshmi Devi,M.E.,Ph.D \\ Assosiate Professor \& HOD Department. of EEE Sri Venkatesa Perumal college of Engg \& Tech,Puttur \\ Professor, Dept. of Electrical \& Electronics Engineering, Sri Venkateswara University College of \\ Engineering ,Tirupati
}

\begin{abstract}
A new converter transformer and an inductive filtering method are presented to solve the existing problems of the traditional converter transformer and the passive filtering method of the high-voltage direct current (HVDC) system. It adopts the ampere-turn balance of the transformer as the filtering mechanism. A tap at the linking point of the prolonged winding and the common winding of the secondary windings is connected with the LC resonance circuit. It can realize the goal that once the harmonic current flows into the prolonged winding, the common winding will induct the opposite harmonic current to balance it by the zero impedance design of the common winding and the proper configuration of LC parameters, so there will be no inductive harmonic current in the primary winding. Moreover, the reactive power that the converter needs can be partly compensated in the secondary winding. Simulation results have verified the correctness of the theoretical analysis. The new converter transformer can greatly reduce the harmonic content in the primary winding, loss, and noise generated by harmonics in the transformer, and the difficulty of the transformer's insulation design.

Index Terms:Filtering mechanism, harmonic, high-voltage direct current (HVDC), inductive filtering, new converter transformer
\end{abstract}

\section{Introduction}

The high-direct current (HVDC) transmission system has been widely used in remote and large power transmission, submarine cable transmission, and domain electric network interconnection [1]-[3]. HVDC transmission system is always made up of a rectifier station, a dc line, and an inverter station. During the commutating process, a large number of harmonics will be generated by the nonlinear load. Therefore, it is necessary to carry out harmonic suppression. The traditional HVDC ac passive power filters (PPF) are always placed at the converter transformer's primary side (grid side), and the transformer will be adversely affected by harmonics, which causes a series of problems, such as additional harmonic loss, heat, vibration, and noise [1], [4]-[7]. In addition, in order to avoid series/parallel resonance between parallel PPF and system impedance, the traditional PPF cannot reach its tuned point, which greatly affects the filtering effect [8]-[10]. The active power filter (APF) has better filtering effect than the passive power filter (PPF), but APF needs a complex regulation and control system, especially a large power harmonic-generating source, which is inapplicable in current HVDC transmission's ac system [11]-[13]. A patent named coupling-compensation and harmonicshielding converter transformer, that is, the new converter transformer, proposes an ideal solution to harmonic suppression.

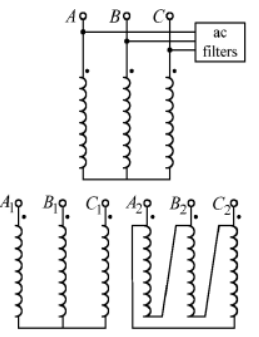

(a)

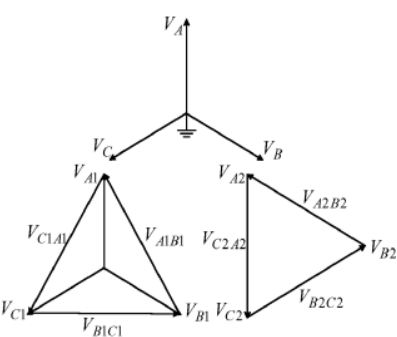

(b)

Fig. 1. Traditional converter transformer with ac filters.

(a) Wiring mode. (b) Voltage phasor diagram.

\section{Problems Of Traditional Converter Transformer's Wiring Mode And Ac Filtering Scheme}

As Fig. 1 shows, the traditional converter transformer and ac passive filtering method are commonly used in 12-pulse HVDC system. It is clear that the transformer adopts wye/wye/delta wiring, and ac filters are placed at the transformer's primary side. Although this kind of converter transformer and passive filters are widely applied in HVDC systems, these structures and designs still have some disadvantages. 
1) In HVDC transmission systems, the converter is the main harmonic-generating source. A three-phase bridge converter usually generates characteristic harmonic currents at the ac side because of the turning of the thyristors [14]. The noncharacteristic harmonic currents can also be generated due to some factors, such as various unbalances in ac voltages, system impedance, and transformer parameters [15]. All the harmonic currents will flow in the primary and secondary windings of the traditional converter transformer, which increases the transformer's additional heat, vibration, and noise. As a result, it increases the added loss, the difficulty of insulating design, the capacity of the transformer, and the margin of the design capability, which increases the cost of the traditional converter transformer.

2) In the ac system of HVDC, traditional passive filtering is the main method of harmonic suppression. However, it still has several disadvantages. The most serious one is that the series/parallel resonance may occur between the system impedance and the passive power filters. This series/ parallel resonance will result in the amplification of harmonic current and harmonic voltage, and it may damage the passive power filters and neighboring power equipment [16], [17]. To avoid the resonance of the passive power filters, the tuned frequency of passive power filters is designed slightly away from the dominant harmonic frequency. However, it will degrade the performance of the passive power filter, and the filtering effect of the traditional passive filter cannot be optimal.

\section{Technical Characteristics Of New Converter Transformer And Corresponding Inductive Filtering Method}

Fig. 2 shows the new converter transformer and the corresponding inductive filtering system, in which, (a) shows the wiring mode of the transformer, and its secondary winding adopts prolonged-delta wiring. To facilitate our discussion, the winding of $A_{i}-a_{i}, B_{i}-b_{i}, C_{i^{-}} c_{i}(i=1,2)$ is called aprolonged winding, and the winding of $a_{1}-b_{1}, b_{1}-c_{1}, c_{1}-a_{1}, a_{2}-c_{2}, b_{2}-a_{2}, c_{2}-a_{2}$ is called common winding. (b) shows the transformer's voltage phasor diagram, which is used to discuss the phase-shifting of the new transformer. (c) shows the arrangement of the inductive filters. As can be seen from (c), a tap at the linking point of each single-phase prolonged winding and common winding is connected with double-tuned (DT) filters. The inductive filtering method will be discussed later on in this paper.

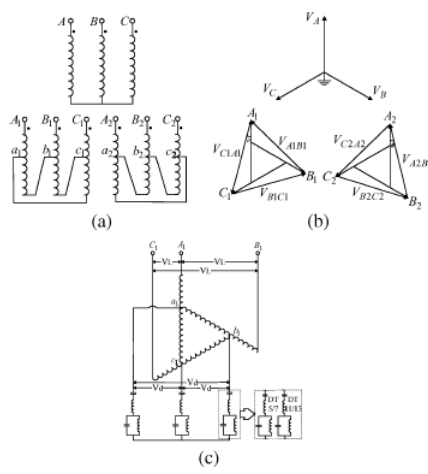

Fig. 2. New converter transformer and corresponding inductive filtering system. (a) Wiring mode . (b) Voltage phasor diagram. (c) Arrangement of filters.

\section{A. Phase-Shifting Principle}

In order to satisfy the demand of 12-pulse HVDC, the converter transformer has to supply 12-phase commutating line voltage. The secondary winding of the traditional transformer adopts wye/delta wiring, and the phase angle difference between the wye winding's line-voltage and the delta winding's line-voltage has to be $30^{\circ}$, which is shown in Fig. 1(b). As for the new converter transformer, according to Fig. 2(b), we can set the phase angle difference between the line-voltage $\mathrm{V}_{\mathrm{C}-\mathrm{A}}$ and the $\mathrm{V}_{\mathrm{C1}-\mathrm{A} 1}$ to $-15^{\circ}$, and set the phase angle difference between the line-voltage $\mathrm{V}_{\mathrm{C}-\mathrm{A}}$ and the $\mathrm{V}_{\mathrm{C} 2-\mathrm{A} 2}$ to $+15^{\circ}$. In this way, the phase angle difference between the linevoltage $\mathrm{V}_{\mathrm{C} 1-\mathrm{A} 1}$ and the $\mathrm{V}_{\mathrm{C} 2-\mathrm{A} 2}$ is $30^{\circ}$. So we can deduce that the phase-shifting angle $\Theta$ should be $15^{\circ}(\Pi / 12)$. Set that the voltage value of the primary winding of the new converter transformer is $\mathrm{V}_{1}$, the voltage value of the secondary prolonged winding is $\mathrm{V}_{2}$, and the voltage value of the secondary common winding is $\mathrm{V}_{3}$; then, according to Fig. 2(b) and sine rule, the following can be obtained:

$$
\begin{aligned}
\mathrm{V}_{3} / \sin (\Pi / 12) & =\left(\mathrm{V}_{3}+\mathrm{V}_{2}\right) / \sin (\Pi / 4) \\
& =\sqrt{ } 3 \mathrm{~V}_{1} / \sin (2 \Pi / 3)
\end{aligned}
$$

According to the above equation, the turn-ratio can be obtained as follows 


$$
\begin{aligned}
& \mathrm{K}_{3}=\mathrm{N}_{3} / \mathrm{N}_{1}=\mathrm{V}_{3} / \mathrm{V}_{1}=0.5176 \\
& \mathrm{~K}_{2}=\mathrm{N}_{2} / \mathrm{N}_{1}=\mathrm{V}_{2} / \mathrm{V}_{1}=0.8966
\end{aligned}
$$

in which $\mathrm{K}_{3}, \mathrm{~K}_{2}$ respectively, represent the turn-ratio of the secondary prolonged winding and the common winding to primary winding. $\mathrm{N}_{1}, \mathrm{~N}_{2}, \mathrm{~N}_{3}$ and are the turn number of the primary winding, the secondary common winding, and the prolonged winding, respectively.

In the actual HVDC systems, the new converter transformer can adopt the single-phase three-winding method. As long as the relation of the turn-ratio satisfies (2), the new converter transformer can supply 12-phase commutating line voltage and satisfy the commutating demand of the 12-pulse converter

\section{B. Self-Coupling Action}

The secondary prolonged winding and the common winding of the new converter transformer adopt self-coupling connection, which is similar to the series winding and the common winding of autotransformer [17], [18]. According to Fig. 2(c), set that the output line-voltage is $V_{L}$, the voltage of the common winding is $\mathrm{V}_{\mathrm{d}}$ and the voltage of the prolonged winding is $\mathrm{V}_{\mathrm{e}}$; then, the following voltage phasor diagram in Fig. 3 can be obtained.

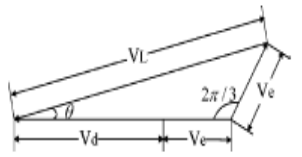

Fig. 3. Voltage phasor diagram for secondary winding's analysis

According to cosine rule, the output line-voltage can be expressed as follows

$\mathrm{V}_{\mathrm{L}}^{2}=\left(\mathrm{V}_{\mathrm{e}}+\mathrm{V}_{\mathrm{d}}\right)^{2}+\mathrm{V}_{\mathrm{e}}^{2}-2 \mathrm{~V}_{\mathrm{e}}\left(\mathrm{V}_{\mathrm{e}}+\mathrm{V}_{\mathrm{d}}\right) \cos (2 \mathrm{n} / 3)$

Then, the voltage of the secondary prolonged winding is deduced as follows:

$\mathrm{V}_{\mathrm{e}}=-\mathrm{V}_{\mathrm{d}} / 2+\sqrt{ }\left(\left(\mathrm{V}_{\mathrm{L}}^{2} / 3\right)-\left(\mathrm{V}_{\mathrm{d}}^{2} / 12\right)\right)$

The secondary prolonged and common winding of the new converter transformer is electromagnetic coupling, which is similar to the series and commonwinding of the autotransformer. When the prolonged winding and the common winding maintain magnetic force balance, we can obtain the following relation:

$$
\mathrm{Ve} \mathrm{Ie}=\mathrm{V}_{\mathrm{d}} \mathrm{I}_{\mathrm{d}}
$$

in which $I_{e}$ and $I_{d}$ are the root-mean-square (RMS) current of the secondary prolonged winding and the common winding, respectively.

Fig. 2(c) shows that the current of the secondary prolonged winding is equal to the output current, and its electromagnetic capacity can be expressed as follows:

$$
\mathrm{S}_{\mathrm{e}}=3 \mathrm{~V}_{\mathrm{e}} \mathrm{I}_{\mathrm{o}}
$$

Meanwhile, the output capacity can be expressed as follows:

$$
S_{\mathrm{o}}=\sqrt{ } 3 \mathrm{~V}_{\mathrm{L}} \mathrm{I}_{\mathrm{o}}
$$

Then, the ratio coefficient can be obtained as follows, which is used to analyze the material utilizing ratio of the transformer:

$$
\alpha=\mathrm{S}_{\mathrm{e}} / \mathrm{S}_{\mathrm{o}}=\sqrt{ } 3 \mathrm{~V}_{\mathrm{e}} / \mathrm{V}_{\mathrm{L}}
$$

Assuming that the output line-voltage value $\mathrm{V}_{\mathrm{L}}$ the new converter transformer is $110 \mathrm{kV}$, and voltage value of the secondary common winding is $35 \mathrm{kV}$, then, according to (4)-(8), we can obtain the ratio coefficient $\alpha=0.681<1$, which indicates that new converter transformer is material saving. 


\section{Inductive Filtering Mechanism}

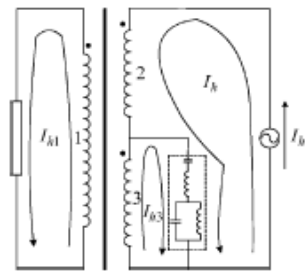

Fig. 4. New converter transformer's single-phase harmonic model.

Fig. 4 shows the single-phase model of the new converter transformer, which is used to analyze the inductive filtering mechanism. In this figure, $\mathrm{I}_{\mathrm{h}}$ indicates the harmonic current source, which is also the harmonic current of the secondary prolonged winding. $\mathrm{I}_{\mathrm{h} 1}$ and $\mathrm{I}_{\mathrm{h} 3}$ indicate the harmonic current of the primary winding and the secondary common winding, respectively. Because of the harmonic current $I_{h}$ of the secondary prolonged winding, the primary winding and the secondary common winding will induce harmonic current $I_{h 1}$ and $\mathrm{I}_{\mathrm{h} 3}$ to balance $\mathrm{I}_{\mathrm{h}}$.

According to magnetic force balance, the following results:

$$
\mathrm{N}_{2} \mathrm{I}_{\mathrm{h}}=\mathrm{N}_{3} \mathrm{I}_{\mathrm{h} 3}+\mathrm{N}_{1} \mathrm{I}_{\mathrm{h} 1}
$$

in which $\mathrm{N}_{1}, \mathrm{~N}_{2}, \mathrm{~N}_{3}$, and are the turn number of the primary winding, the secondary prolonged winding, and the common winding, respectively.

If the harmonic ampere-turns of the secondary prolonged winding and those of the common winding can keep balance, then $\mathrm{I}_{\mathrm{h} 1}=0$, that is, there will be no induction harmonic current in the primary winding. That is to say, the harmonic currents only flow in the secondary winding of the new transformer. To realize the inductive filtering method, it not only needs the full tuning design of the tapping filter, but also needs the zero inductance design of the secondary common winding of the new converter transformer, which will be analyzed in the following equivalent circuit of the single-phase transformer shown in Fig. 5.

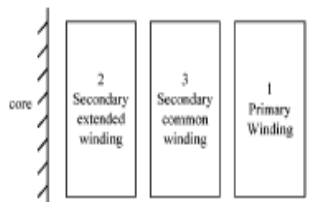

(a)

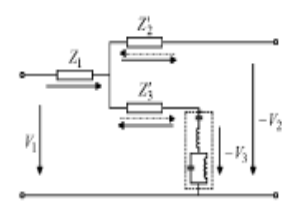

(b)

Fig. 5. Single-phase model of the new converter transformer. (a) Winding arrangement. (b) Equivalent circuit.

Fig. 5(a) shows the winding arrangement of the single-phase model of the new converter transformer. According to short-circuit test, we can measure the short-circuit impedance $Z_{12}, Z_{13}$ and $Z_{23}$. Then, the equivalent impedance shown in Fig. 6(b) can be expressed as follows:

$$
\begin{aligned}
& \mathrm{Z}_{1}=0.5\left(\mathrm{Z}_{12}+\mathrm{Z}_{13}-\mathrm{Z}_{23}{ }^{1}\right) \\
& \mathrm{Z}_{2}{ }^{1}=0.5\left(\mathrm{Z}_{12}+\mathrm{Z}_{23}{ }^{1}-\mathrm{Z}_{13}\right) \\
& \mathrm{Z}_{3}{ }^{1}=0.5\left(\mathrm{Z}_{13}+\mathrm{Z}_{23}{ }^{1}-\mathrm{Z}_{12}\right)
\end{aligned}
$$

By regulating the winding arrangement shown in Fig. 5(a), it can realize the goal that the impedance $\mathrm{Z}_{3}{ }^{1}$ of the secondary common winding is approximately equal to 0 (the resistance can be ignored for highcapacity converter transformers). In Fig. 5(b), the solid arrow and the virtual arrow, respectively, indicate basic frequency current and harmonic frequency current. Under the specific harmonic frequency of the harmonic current that needs suppressing, both of the double-tuned filter and the harmonic impedance of the secondary common winding are approximately 0 , so the harmonic current mainly flows into the branch of the secondary common winding, and there is approximately no harmonic current in the primary winding.

In addition, under the fundamental frequency, the impedance of the filter is capacitive, thus providing reactive power compensation. 


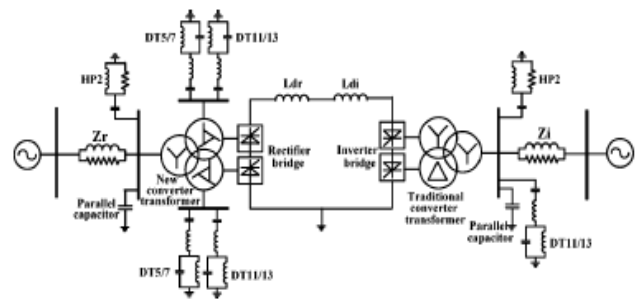

Fig. 6. New HVDC transmission analogy system with new converter transformer in rectifier station and traditional converter transformer in inverter station.

\section{A. Simulation Model}

\section{System Simulation Study}

In order to prove the correctness of the above analyses, according to the new HVDC transmission testing system shown in Fig. 6, we have established a system simulation model by using MATLAB/SIMULINK. Fig. 6 shows the rectifier station with the new converter transformer and in the corresponding inductive filtering method and the inverter station with the traditional converter transformer and in the passive filtering method. It is necessary to clarify that the double-tuned filter (DT5/7) is not needed when we consider suppressing fifth and seventh harmonic currents in the wiring method of the new converter transformer in the rectifier station. Here, due to the high content of fifth and seventh harmonics, in order to remove their negative effect of fifth and seventh harmonics on the converter transformer, we have designed the DT5/7. In Fig. 7, HP2 indicates the second-order high-pass filter; $Z_{\mathrm{r}}$ and $\mathrm{Z}_{\mathrm{i}}$, respectively, indicate the system impedance of the rectifier and the inverter side, and and $\mathrm{L}_{\mathrm{dr}}, \mathrm{L}_{\mathrm{di}}$ respectively, indicate the inductance of the rectifier and the inverter side.
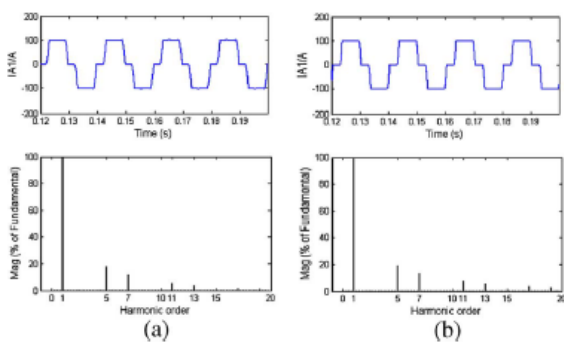

Fig. 7. Phase current fast Fourier transform (FFT) of the secondary terminal of the traditional and the new converter transformer.

(a) FFT of secondary phase current $\mathrm{I}_{\mathrm{A} 1}$ corresponding to Fig. 1.

(b) FFT of secondary phase current $\mathrm{I}_{\mathrm{A} 1}$ corresponding to Fig. 2 .
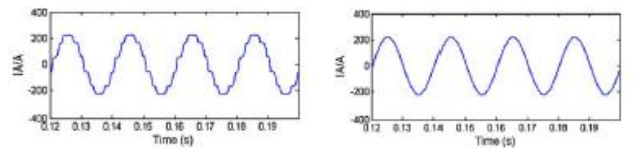

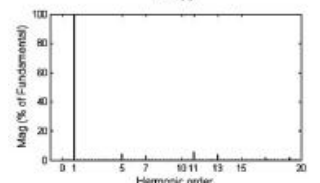

(a)

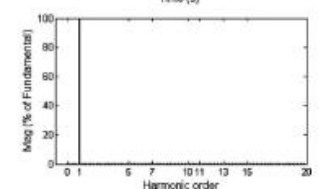

(b)

Fig. 8. Phase current FFT of the primary terminal of the traditional and the new converter transformer.

(a) FFT of primary phase current $\mathrm{I}_{\mathrm{A}}$ corresponding to Fig. 1.

(b) FFT of primary phase current $\mathrm{I}_{\mathrm{A}}$ corresponding to Fig. 2.

\section{B. Contrast Analysis of Simulation Results}

Fig. 7 shows the phase current FFT of the secondary terminal of the traditional converter transformer and that of the new converter transformer. It can be seen that the harmonic content of each order of the traditional and the new converter transformers is similar, which is determined by the nonlinear load, that is, the converter. However, as for the primary phase current of the transformer shown in Fig. 8, it can be seen that the primary phase-current waveform of the new converter transformer is better than that of the traditional one, which is determined by the wiring method of the transformer and by the filtering method. We can see that adopting the new winding wiring and the inductive filtering method can effectively suppress the 5th, 7th, 11th, 
and 13th harmonic currents that only flow in the secondary winding of the new transformer, so the THD shown in Fig. 8(b) is lower than that in Fig. 8(a). Table I shows the FFT value of the exact harmonic contents of Figs. 7 and 8 , which further proves the correctness of the above analysis.

TABLE I: Comparison of the harmonic content of the secondary sides of the new and the traditional converter transformers

\begin{tabular}{cccccc}
\hline \hline \multirow{2}{*}{$\begin{array}{c}\text { Harmonic } \\
\text { order }\end{array}$} & \multicolumn{2}{c}{$\begin{array}{c}\text { Traditional converter } \\
\text { transformer }\end{array}$} & & \multicolumn{2}{c}{ New converter transformer } \\
\cline { 2 - 3 } \cline { 5 - 6 } \cline { 5 - 6 } & Secondary side & Primary side & & Secondary side & Primary side \\
\hline 5 & 19.19 & 4.05 & & 18.03 & 0.08 \\
7 & 13.08 & 3.34 & & 11.96 & 0.04 \\
11 & 7.44 & 5.33 & & 5.58 & 0.09 \\
13 & 5.44 & 3.66 & & 3.73 & 0.06 \\
\hline \hline
\end{tabular}

Fig. 9 shows the phase current FFT at the grid side of the rectifier and the inverter station, respectively.We can see that the waveform of the phase current in Fig. 9(a) is better than that in Fig 9(b), which is caused by the new inductive filtering method Considering the effect of the system impedance, the resonance point of the passive filters cannot be reached. So the filtering effect is not ideal, as shown in Fig. 9(b). While adopting the inductive filtering method, the harmonic currents are confined by the coupling-windings of the new converter transformer, so the resonance point of the tap filters can be reached. Therefore, we can obtain the ideal phase current waveform at the grid side shown in Fig. 9(a).Acomparison of the exact harmonic contents is shown in Table II.

TABLE II : Comparison of the harmonic content of the grid sides of the rectifier station and the inverter station

\begin{tabular}{ccc}
\hline Harmonic order & $\begin{array}{c}\text { Inverter station's grid side } \\
\text { (Using traditional converter } \\
\text { transformer) }\end{array}$ & $\begin{array}{c}\text { Rectifier station's grid side } \\
\text { (Using new converter } \\
\text { transformer) }\end{array}$ \\
\hline 5 & 4.02 & 0.07 \\
7 & 3.33 & 0.04 \\
11 & 4.89 & 0.08 \\
13 & 1.89 & 0.06 \\
\hline
\end{tabular}
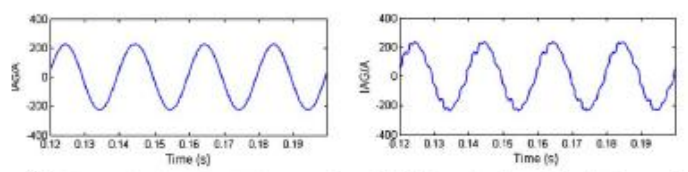

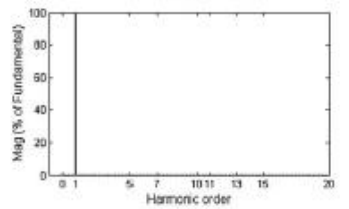

(a)

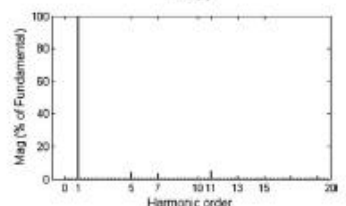

(b)

Fig. 9. Phase current FFT at the grid side of the rectifier station and the inverter station, respectively.

(a) FFT of phase current $\mathrm{I}_{\mathrm{AG}}$ at the grid side of the rectifier station corresponding to Fig. 6 .

(b) FFT of phase current $\mathrm{I}_{\mathrm{AG}}$ at the grid side of the inverter station corresponding to Fig. 6.

\section{Conclusion}

In 12-pulse HVDC transmission systems, the secondary windings of the new converter transformer adopt prolonged delta wiring, which brings about good symmetrical characteristics to its structure. Each phase short-circuit impedance can be equal. It can facilitate the reliable commutation and the sound operation of the converter. The equivalent impedance of the secondary common winding is approximately 0 , which provides good conditions for inductive filtering. The resonance point of the tap filters of the new transformer can be reached without the consideration of the effect of the system impedance. Simulation results verify the correctness of our theoretical analysis, and show that the filtering effect of the inductive filtering method is better than that of the traditional passive filtering method. Adopting the new converter transformer and the corresponding inductive filtering method can optimize the structure of HVDC transmission systems, greatly 
reducing the negative effect of harmonic on the operation of the transformer and improving the filtering effect at the ac side of HVDC systems.

\section{References}

[1]. B. R. Anderson, "HVDC transmission-opportunities and challenges," in AC and DC Power Transmission, 2006, Proc. 8th Inst. Elect. Eng. Int. Conf., Mar. 28-31, 2006, pp. 24-29.

[2]. C. Wolff and T. Elberling, "The Kontek HVDC link between denmark and germany," in Proc. IEEE Power Eng. Soc. Winter Meeting, Jan. 23-27, 2000, vol. 1, pp. 572-574.

[3]. B. Gemmel and J. Loughran, "HVDC offers the key to untrapped hydro potential," IEEE Power Eng. Rev., vol. 22, no. 5, pp. 8-11, May 2002.

[4]. J. Alan, C. Forresta, and B. Allard, "Thermal problems caused by harmonic frequency leakage fluxes in three-phase, three-winding converter transformers," IEEE Trans. Power Del., vol. 19, no. 1, pp. 208-213, Jan. 2004.

[5]. J. Alan and C. Forrest, "Harmonic load losses in HVDC converter transformers," IEEE Trans. Power Del., vol. 6, no. 1, pp. 153-157, Jan. 1991.

[6]. M. J. Heathcote, The J\&P Transformer Book, 25 ed. Oxford, U.K.: Reed, 1998

[7]. K. Eckholz and P. Heinzig, "HVDC-transformer-a technical challenge," in Proc. IEEE Int. Conf. Power Syst. Technol., Oct. 13-17, 2002, vol. 1, pp. 547-551.

[8]. J. C. Das, "Passive filters-potentialities and limitations," IEEE Trans. Ind. Applicat., vol. 40, no. 1, pp. 232-241, Jan.-Feb. 2004.

[9]. H.-L. Jou, J.-C. Wu, and K.-D. Wu, "Parallel operation of passive power filter and hybrid power filter for harmonic suppression," Proc. Inst. Elect. Eng. Generation, Transmission, Distribution, vol. 148, no. 1, pp. 8-14, Jan. 2001.

[10]. D. Rivas, L. Moran, J. W. Dixon, and J. R. Espinoza, "Improving passive filter compensation performance with active techniques," IEEE Trans. Ind. Electron., vol. 50, no. 1, pp. 161-170, Feb. 2003.

[11]. W. Zhang, A. Aberg, U. Jonsson, and O. Loof, "Active DC filter for HVDC system-A test installation in the Konti-Skan DC link at Lindome converter station,” IEEE Trans. Power Del., vol. 8, no. 3, pp. 1599-1606, Jul. 1993.

[12]. T. Westerweller, M. Pereira, H. Huang, and G. Wild, "Performance calculation and operating results of active AC harmonic filters for HVDC transmission systems," in Proc. IEEE Power Eng. Soc. Summer Meeting, Jul. 15-19, 2001, vol. 1, pp. 337-342.

[13]. D. Basic, V. S. Ramsden, and P. K. Muttik, "Harmonic iltering of high-power 12-pulse rectifier loads with a selective hybrid filter system," IEEE Trans. Ind. Electron., vol. 48, no. 6, pp. 1118-1127, Dec. 2001.

[14]. R. Zhena, Z. Yan, and D. Baoming, "Optimization model and algorithm of type-c damped filter in high voltage direct current transmission system," in Proc. CSEE, Dec. 2002, vol. 22, no. 22, pp. 123-126.

[15]. C.-K. Kim, B.-M. Yang, Y.-H. Kim, and H.-W. Rhem, "HVDC performance analysis according to ER-filter and single tuned filter," in Proc. 29th Annu. Conf. IEEE Ind. Electron. Soc., Nov. 2-6, 2003, vol. 3, pp. 2655-2659.

[16]. H.-L. Jou, J.-C. Wu, and K.-D. Wu, "Parallel operation of passive power filter and hybrid power filter for harmonic suppression," Proc. Inst. Elect. Eng. Generation, Transmission, Distribution, vol. 148, no. 1, pp. 8-14, Jan. 2001.

[17]. B. Singh, G. Bhuvaneswari, and V. Grag, "T-connected autotransformer- based 24-pulse ac-dc converter for variable frequency induction motor drives," IEEE Trans. Energy Conv., vol. 21, no. 3, pp. 663-672, Sep. 2006

Author's detail

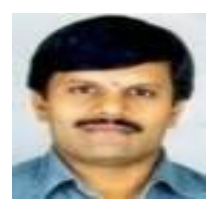

Mr.A.Hema Sekhar Currently Pursuing Ph.D.degree in SVU College of Engineering .He is Presently working as Associate Professor in Sri Venkatesa Perumal College of Engineering \& Technology,Puttur. he received his B.Tech in EEE from JNT University,Hyderabad,at SVEC,A.Rangampet.he received his M.Tech in PSOC from SV University College of Engineering,Tirupati. His area of interest are power systems,Distribution Systems,Electrical Machines and Power system Stability \& Control,power system optimizations

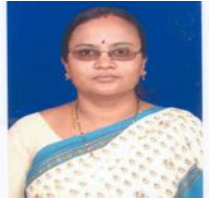

Mrs.A.Lakshmi Devi She is currently working as Professor in SV University College of Engineering,Tirupati.She received her B.Tech in Electrical \& Electronics Engineering from SV University College,Tirupati and M.E from IISc,Bangolore and Ph.D from SV University ,Tirupati. Her Area of interest are load flow studies,load frequency control,Reactive power control,Power system operation \& Control and power system stability. 